terms of industrial practice. So translated, it might be worth submitting to tests acceptable to the statistician and methodologist as theoretically sound, and acceptable to management as workable in practice.

An even more fundamental challenge to science and management would seem to have been implied by the argument of the third contributor to the symposium. According to Mr. Adam Curle, who approached the subject from the point of view of an anthropologist, the very existence of an incentives problem is symptomatic of a malady in modern society. In primitive societies necessary work is as automatic as eating or sex ; and our present problem is nothing less than that of recreating these conditions. This, of course, is not to be achieved by a mere regression to the original order. The need is for a new social order "in which the anxious tensions resulting in withdrawal and isolation from the group can be reduced". We need to provide the conditions of a 'psychological' as well as those of a constitutional democracy. Then the incentives problem would again disappear. Nothing very specific was suggested as to the way in which this might be done; but it would depend on close collaboration between social scientists of many different kinds. The results obtained in army resettlement units, it was suggested, gives some indication of the lines along which to work.

Mr. Alec Rodger, through what at first appeared to be an excursion into lexicography, raised an issue of the greatest moment. The term 'incentive', he pointed out, is commonly used by industrialists and defined in dictionaries by reference to incitements that are essentially passing rather than permanent in effect. On the other hand, the preceding speakers had appeared to be almost exclusively concerned with the conditions that continuously maintain an optimum level of effort throughout the working weeks and years. "Admittedly we need long-term programmes for the improvement of morale, for in the long run this is the only manner in which high industrial productivity is likely to be properly established and sustained; but in our present plight we cannot disdain to use any device which shows promise of yielding quick results." An example of the sort of research which was needed was quoted from some studies of the Social Survey which had given indications that different types of motivation operate at different intelligence levels.

Speaking with intimate and first-hand experience, Mr. Rodger had things to say on the functions of the psychologist in relation to management and administration. The root of the problem, he suggested, lies in the fact that the technical adviser will often miss the opportunity both to understand the principles on which his colleagues work and of dealing with critical situations unless at the decisive moment he is prepared to do the job himself, since he can act with insight and confidence when they cannot.

The discussion as a whole, however inconclusive and however limited in suggestions likely to yield 'quick results' it may have seemed, served a useful purpose in revealing something of the total dimensions of the problem. There is clearly, and by general agreement, a need for expansion and intensification of research and development in which a due balance is preserved between the advance of knowledge and the application of what is already known. There is need for advances both in fundamental research and in the development of practical techniques. It is probably through the development of managerial techniques for using what is already known that the 'quick results' are most likely to be obtained. But it is here, more than anywhere else, that Mr. Rodger's distinction needs to be kept in mind. There is a widespread view among industrial psychologists that the benefits derived from temporary incitements are often paid for dearly through their subsequent effects in fatigue and reaction. If they be correct in this opinion, the use of such expedients can be defended only in an emergency the passing nature of which can be predicted with some assurance. Here, as elsewhere, the best results are likely to be achieved by those who combine a sense of the need for quick results with the wider and the longer view. Perhaps this combination is not to be found in any single scientific or managerial group; and the need will only be met by the kinds of collaboration concerning which all the speakers were agreed. It is accordingly somewhat sobering to reflect that in spite of the widespread interest in the problem, the number of workers actually engaged in relevant research at this time is extremely small.

C. A. MACE

\section{TRANSMISSION OF EFFECTS FROM THE ENDINGS OF NERVE FIBRES}

\section{DISCUSSION on the transmission of effects} A from the ends of nerve fibres occupied an afternoon session of Section I (Physiology) of the British Association on September 9. Sir Henry Dale introduced the discussion by saying that we may agree on the assumption that the liberation of one or another chemical substance with a specific stimulating action is the means by which, in vertebrates, nerve impulses are transmitted from the endings of all efferent fibres of the peripheral nervous system, whether pre- or post-ganglionic fibres of the involuntary nerves, or motor fibres of the voluntary nerves. But there remains a wealth of problems still open to discussion concerning details of such a process.

Since two of the speakers were dealing with the extension of this theory to the vast complex of synaptic junctions in the central nervous system, Sir Henry Dale first discussed this problem. The exciting possibilities presented by studies in this field, he said, have acted as both a stimulus and a deterrent. When, more than twenty years ago, he told Sir Charles Sherrington, then already in retirement, about the evidence that had been obtained at that time in his laboratory for the transmitter function of acetylcholine at preganglionic and voluntary motor nerve endings, Sir Charles' immediate reaction was to insist that a process observed at peripheral synapses must furnish some kind of analogy for events at those of the central nervous system. Referring to the experimental attempt of Dr. W. Feldberg to distinguish central synapses at which transmission may be cholinergic from others at which it is not, Sir Henry Dale said that such a differentiation raises the question as to what the transmitter may be at these others. For it is difficult to suppose that synapses in the central nervous system can differ among themselves so fundamentally in function that transmission at some should be cholinergic and at others involve no kind of chemical agent. Referring to the experiments of Mr. J. W. S. Pringle and Mr. G. M. Hughes, by which the discussion is extended to the nerve ganglia of the ventral chain in an insect, he again pointed out 
that we should scarcely expect to find that the transmission across synaptic junctions in an insect's ganglion would involve a process fundamentally different in kind from that which is effective at vertebrate synapses.

Turming to the recent developments of evidence for the nature of the transmitter substances themselves in the peripheral vertebrate system, Sir Henry Dale discussed several outstanding and very acute problems in this field of research. For cholinergic transmission the released agent is acetylcholine itself, but there has never been the same certainty with regard to the transmitter of adrenergic fibres, adrenaline. "This problem has recently acquired a new aspect through the evidence produced by U. von Euler, that the sympathomimetic agent extractable from sympathetic nerves or from the spleen, appears, indeed, to be chiefly nor-adrenaline rather than adrenaline, and Gaddum's finding that the substance released in the spleen when its adrenergic nerve is stimulated is likewise, for the most part, the primary amine. One is tempted to speculate whether a renewed investigation of the suprarenal gland might not reveal nor. adrenaline as a constituent of its medulla as well as its long known N-methylated homologue, adrenaline." We should further keep in mind that the list of the transmitters, even at the peripheral cytoneural junctions, should not yet be regarded as finally restricted to the two concerned with the recognized cholinergic and adrenergic processes of transmission. Histamine may have to be considered as contributing, at least, to the so-called antidromic vasodilator effect, a possibility envisaged by Lewis and his co-workers and supported by evidence from Ungar and others.

The next problem taken up concerned the presence of the transmitter substances and the relevant enzymes for their synthesis and destruction along the whole course of a nerve fibre. According to Sir Henry Dale, it does not seem possible to accept the suggestion so vigorously urged in recent years by Dr. Nachmansohn and his associates. According to these speculations, acetylcholine would not only be responsible for the transmission from nerve ending to a secondary neuron or an effector cell, but also for the propagated nerve impulse along the nerve fibre. "Such a conception offers, of course, the kind of intellectual satisfaction which many minds obtain from a simplifying and co-ordinating generalization. There is, however, a remarkable lack of unequivocal evidence to support it directly, while the ingenuity of its supporters is sorely taxed to discover even plausible ways of escape from the facts which contradict it." Only some nerve fibres are cholinergic. The theory postulates a stimulating depolarizing action of acetylcholine on the nerve fibres. But as Lorenté de No has shown recently, the nerve fibre in continuity is as indifferent to acetylcholinechloride, even in isotonic solution, as to cane sugar, provided only sufficient physostigmine, or other anticholinesterase, is added, to prevent the esterase in the nerve from hydrolysing the acetylcholine, and thus liberating acetic acid ions from it in a harmful concentration. We may, however, have to consider the possibility, put forward with all reserve by Sir Henry Dale, that the transmitter which we find distributed along the fibres represents a kind of reserve needed for the regular and immediate replenishment of the depots at the endings, and that the passage of impulses along the fibres to their endings would somehow facilitate a drift of the transmitter down them in the same direction.
The last problem dealt with by Sir Henry Dale concerned the presence or absence of the transmitter substances, not along the nerve fibres, but in the protoplasma or neurosoma of the nerve cells them. selves from which the axons in question originate.

Prof. F. R. Miller, of the University of Western Ontario, then described his discovery of the central stimulating actions of acetylcholine and eserine, effects which are consistent with the suggestion, made so early as 1934 by Sir Henry Dale, that acetylcholine may be concerned in the transmission at central synapses. Even in the experiments with eserine, acetylcholine is probably the actual stimulating agent, because the central actions of eserine, like its peripheral ones, are also probably more or less fully accounted for by its power of inhibiting cholinesterase, the enzyme which destroys acetyl. choline, thus leading to its accumulation at the synapses.

The technique adopted by Prof. Miller in these experiments consisted in soaking small pieces of filter paper in a solution of acetylcholine or eserine and applying them to the cerebral cortex of cats and rabbits. Eserine applied in this way to the centres for the fore- or hind-limbs evoked within a few seconds motor effects of rapidly increasing intensity in the corresponding limb of the opposite side. The cortical electrogram was modified. The normal large slow waves were replaced by small fast waves suggesting an asynchronous firing of cortical neurons. Acetylcholine similarly applied to a previously eserinized cortex induced large 10 per second spikes in the cortical electrogram, together with motor effects in the muscle units, as shown with the cathode ray oscillograph by Miller, Stavraky, Woonton, Wilkey and Luke. According to Miller, each 'acetylcholine spike' suggests a synchronous firing of a number of cortical neurons under the influence of "cells with short axons", each of which controls a number of pyramidal cells.

Particularly striking were more recent experiments in which Prof. Miller applied dilute solutions of acetylcholine, with the same technique, to the floor of the fourth ventricle. These experiments were performed on decerebrate cats which had received an injection of eserine. The local application of acetylcholine stimulated the inspiratory centre, and later on caused convulsive discharges from the hypoglossus nucleus, shown by powerful retractions of the tongue. These effects, like the comparable stimulating actions of acetylcholine on the spinal cord, described by Bülbring and Burn, were abolished by atropine.

Dr. W. Feldberg remarked that he approached the problem of central synaptic transmission by acetylcholine in a different way. Miss M. Vogt and he studied the synthesis of acetylcholine in various rela. tively small but well-defined areas of the brain and medulla. An analysis of the distribution of the enzyme system responsible for the synthesis of acetylcholine in the central nervous system led them to the conclusion that acetylcholine is not the universal central synaptic transmitter, and that often, although by no means always, the arrangement of neurons in the afferent and efferent nervous pathways is such that cholinergic and non-cholinergic neurons alternate with each other. For example, in the voluntary motor pathway, the finding of a high enzyme concentration in the anterior horns, the motor nuclei of the cranial nerves and the anterior roots suggests the cholinergic nature of the lower motor neuron. On the other hand, the 
low values encountered in the pyramidal tracts indicate that the upper motor neuron is not cholin. ergic. In the motor area of the cerebral cortex an intermediate value was found. This might suggest that eholinergic neurons converge on the pyramidal cells. Similarly, the low values found for the posterior roots and their central continuation, the funiculi gracilis and cuneatus, are in agreement with the conception that the first neuron of the afferent sensory pathway is non-cholinergic. However, the relatively high values obtained for the nuclear masses in which these sensory fibres end might be evidence for the cholinergic nature of the second neuron in the sensory pathway.

The third neuron, originating in the thalamus and leading to the cortex, is probably non-cholinergic, as suggested by the low values found for the fibres in the posterior parts of the internal capsule, which at least in man is said to contain the thalamic radiation. Another example was provided by the optic pathway. The retina contains large amounts of the enzyme which synthesizes acetylcholine, whereas the optic nerve is practically free from it. This suggests that acetylcholine is the chemical transmitter at one or more of the synaptic junctions in the retina. Among these junctions may be that to the ganglionic layer from which the non-cholinergic optic nerve originates. The optic fibres end mainly in the lateral geniculate body, and the high enzyme values found for this region may indicate a cholinergic nature of the third neuron in this pathway. Dr. Feldberg stressed the fact that, however attractive such a pattern of a succession of alternating non-cholinergic and cholinergic neurons may be, it would be dangerous to have a conception which is too simplified and diagrammatic. We must realize that if there are two different kinds of neurons in the central nervous system, then on purely statistical grounds there should be a great incidence of such an alternation.

The great number of problems involved in the process of central synaptic transmission and their complexity were brought to light by beautiful experiments on cockroaches reported by Mr. J. W. S. Pringle and Mr. G. M. Hughes. They had passed weak polarizing currents laterally through the metathoracic ganglion of the cockroach. This affected the flexor-extensor balance in such a way that the leg on the negative side flexed while that on the positive side extended. With longitudinal stimulation, ascending currents flexed the legs on both sides of the cock. roach and descending currents encouraged extension. It is interesting that Skoglund had observed similar reaction patterns in corresponding experiments on cats. Mr. Pringle and Mr. Hughes suggest that the weak polarizing current excites internuncial fibres and not the motoneurons, because preparations in which only a single nerve was left attached to the ganglion did not show this differential effect when the polarizing current was applied between ganglion and nerve. In these preparations the negative electrode on the ganglion excited, and the positive inhibited, any resting discharge in the larger motor fibres, irrespective of whether the nerve supplied flexor or extensor muscles.

Concerning the problem of chemical transmission, they pointed out that the evidence available shows that the motor nerves to the muscles are not cholinergic in the Arthropoda. On the other hand, acetylcholine may well have a transmitter function at the central ganglionic synapses, because its application to these ganglia causes a discharge of impulses in the motor nerve fibres. It is further possible that the differential effect of polarizing current is due to the fact that in Arthropoda, as in other organisms, two types of transmitter substances are involved in central synaptic transmission.

At the end of the meeting, Prof. R. J. S. McDowall showed a few slides from his recent experiments on the rat's diaphragm preparation, in which he had obtained a curare-like block of neuromuscular transmission as an effect of lack of glucose.

\section{OBITUARIES}

\section{Dr. William Cullen}

By the death, at the age of eighty-one, of Dr. William Cullen, a prominent figure and a vivid personality has been lost to a wide circle of men actively engaged in the varied pursuits which are related directly and indirectly to chemical technology, to metalliferous mining and to metallurgy.

It would be difficult to enumerate the manifold activities with which his name has been identified over the past fifty years; but these are happily recorded, for the most part, in the numerous papers and addresses which he had contributed to the various scientific and technical bodies with which he was associated. His earlier work was published under the auspices of the Chemical, Metallurgical and Mining Society of South Africa, of which he became president in 1905 . In later years, the Transactions of the Institution of Mining and Metallurgy, the Institution of Chemical Engineers and the Society of Chemical Industry have been enriched by his contributions. By each of these bodies in turn he was elected to the presidential chair.

Dr. Cullen's life-work can be divided into two periods. The first was that of his earlier work in South Africa, commencing with his appointment, in the later stages of the 1899-1902 War, as general works manager, at Modderfontein, of the British South African Explosives Co. While retaining his close association with South African affairs to the end, particularly in regard to educational matters, the second period of his career dates from the time of his return to Great Britain in 1915, when, in association with the late K. B. Quinan and W. MeNab, he was entrusted by Lord Moulton (then directing the Department of Explosives Supply) with the design and lay-out of new explosives factories called for by the exigencies of the First World War.

A Scotsman, reared in the hard school of the west coast and the Clydeside, Cullen received his early training in Glasgow, successively at Hutcheson's Grammar School and at what was then the Andersonian College (now the Royal Technical College). As a chemist, he became a member of the staff of Nobel's and later of Kynochs. It was this early experience of the chemistry of explosives that fitted him for the very prominent part he was destined to play in the vast developments which occurred in the mining industry in South Africa following the termination of the War of 1899-1902. The necessity had already been recognized and to some extent met, for the independence from outside supplies of industrial explosives, and it fell to Cullen's lot to promote this independence in step with the growing and pressing demands. 